\title{
The Dynamic of toxic in acid sulphate soil, planting rice in Mekong Delta, Caused by Natural environmental factors
}

\author{
${ }^{1}$ Ba Le Huy, ${ }^{2}$ Hoan Nguyen Xuan, ${ }^{3}$ Nam Thai Van, ${ }^{4}$ Hiep Dang Tan, ${ }^{5}$ Thanh Le Minh \\ 1,2,4:Ho chi minh City University of Food Industry (HUFI); \\ ${ }^{3}$ :Ho chi minh City University of Technology (Hutech) \\ DOI: 10.29322/IJSRP.11.09.2021.p11752 \\ http://dx.doi.org/10.29322/IJSRP.11.09.2021.p11752
}

\begin{abstract}
Through series of experiments with 4 iterations, with statistical processing of reliability, we see: Toxicity in the environment in acid sulfate soil has very large and complex, this variation depends: 1-To dry out, the amount of toxins increases, which can cause rice death. To submerge the amount of toxins clearly decreased. The role is to flood rather than liming without washing alum. 2- Acid water with $\mathrm{pH}=3.8\left(\mathrm{Al}^{3+}<480 \mathrm{ppm}\right)$ can be used to irrigate rice. If it is contaminated with acid water with $\mathrm{pH}<2.9$, the soil will become acidification after 5-6 days. 3- When the rainfall less than $600 \mathrm{~mm}$, there is a danger toxic effects. But flooded more than $(>7 \mathrm{~cm})$ make to increase yield and reduce toxins clearly, 4-Cover land-by plant and green manure cover reduce toxins. 5- Soil moisture has a great influence on toxic fluctuations, especially the organic layer and pyrite layers of the soil are highly acidification, the aluminum salt and it contained Aluminum salt at 30-40\%, the soil becomes acidified quickly and strongly. 6-The alternating oxidation and redox conditions increase the toxicity, especially the pyrite layer and the organic layer.7- Toxins derived from sediments contain a lot of $\mathrm{S}+\mathrm{Fe}+$ mangrove plant residue along with microbiological activity in the soil, in the condition of calcium deficiency. From there, shape the Pyrite bar, then Jarosite, followed by sulfuric Acid. In conditions of low $\mathrm{pH}$ of the environment $<2, \mathrm{Al} 3+$ will be created. The process of aid eagerly completes the production of ionic poisons: $\mathrm{Al}^{3+}, \mathrm{Fe}^{2+}+, \mathrm{Fe}^{3+}, \mathrm{SO}_{4}{ }^{2-}, \mathrm{pH}<4.0$. And, 7-The correlation of toxic ions is a positive correlation, especially $\mathrm{SO}_{4}{ }^{2-}$ and $\mathrm{Fe}^{2+}, \mathrm{Al}^{3+}$ and $\mathrm{Fe}^{2+}$. So if we can limit one toxin, it can reduce other toxins that are correlated.
\end{abstract}

Index Terms- Acid sulfate soil in Mekong Delta; Toxic Dynamic and transformation; Natural factors, Rice planting; Mekong Delta,

\section{INTRODUCTION}

$\mathrm{O}$ $\mathrm{n}$ acid sulfate soils, it is difficult for plants to live or survive with low productivity, mainly due to toxins in the environment. "The toxins are both high in concentration and constantly fluctuating and very complex. One could say: it is a "quirky match" [1]. However, it still has its own rules for each poison or of a toxic group. Knowing that law, we can avoid harm and take advantage of it to arrange crops, fertilizers, irrigation, plant varieties, ... To partly serve production and research. In another application, we present a portion of the results of our many years of research where each sub-category is one or a combination of studies or experiments. In turn introduce the agents: volatility and characteristics of the volatility.

\section{MATERIALS AND METHODS OF RESEARCH}

1- Soil: Undisturbed acid sulphate soil (not disturbed by cultivation): Soil is very acidic, with $\mathrm{pH}=3,6-4,1 ; \mathrm{Al}^{3+}=500-800$ ppm, at this level, although the plants did not die, the toxicity was also very heavy. From there, people selected varieties resistant to alum, control varian: neutral alluvial soil in Tien River.

2- Tree: Rice plant (good resistance to alum and poor alum tolerance, indicator tree (Eleo Charis dulcis) compared to wild land. The contents of research and experiment: Find out about the fluctuations of toxic substances in the environment due to:

1-Apply lime (gradually increase the amount of fertilizer) compared with the control fertilization; 2-Due to flooded fresh water and dry water.

3-watering alum has different levels of toxicity; 4-Build the bed; 5-Due to rain; 6-do phosphate fertilizer; 7- Acidification of the orginal soil; 8-under alternating redox conditions; 9- Find the correlation between toxins.

4-Arrangement of experiments in pots

Pot size: diameter $r=30$, height: $50 \mathrm{~cm}$; material: crockery, put in a greenhouse (Polie Ethylene) with 5 treatments $(2$ cotrol variants), 4 replicates, layout: sequentially the degree of toxicity: gradually increasing.

5-Field experiments:

- Rice plants: On Nhi Xuan wild land acid sulfate soil, plot: 25m2, the soil remains intact, not plowed, experiment is done 4 times, repeated in random sequence. 
- In conditions need to maintain stable alum toxicity, use natural alum water to adjust

6-Norms of monitoring and analysis: 1-Growth and development of rice plants, especially stage 3-4 true leaves (rotten roots, black, poisoned stems-leaves, ...). 2-Actual yield, and constituent indicators of productivity; and 3-Monitoring the growth and toxicity of Co Nang alum resistant control plant (Eleocharis Dulcis). Monitoring: according to the predetermined time and number of times). Analysis of soil and water environment: $\mathrm{pH}$ (Caloman electrode), $\mathrm{Fe}^{2+}, \mathrm{Fe}^{3+}$ (comparison of color of alpha dipiridin reagent), $\mathrm{Al}^{3+}$ (sokolov), $\mathrm{SO}_{4}{ }^{2-}, \mathrm{PO}_{4}{ }^{3-}$ (Spetronic UV 120).

\section{RESEARCH RESULTS}

Toxicity fluctuation due to flooding and drying up of rice land

Experiments are carried out to test the effects of flooding regularly and periodically. Result:

-With $\mathrm{Fe}^{2+}$ : Treat to submerge $20 \mathrm{~cm}$ for 10 days and then let it dry for 20 days, next, submerge $20 \mathrm{~cm}$ for 23 days and see, at the time of flooding $6-7 \mathrm{~cm}, \mathrm{Fe}^{2+}$ increases, but let the water dry, $\mathrm{Fe}^{2+}$ nor decreased but increased in both floors. That shows that the water dry (but the soil is still saturated with moisture) will remain anaerobic, plus the capillary from the bottom up, making the Fe ${ }^{2+}$ concentration in the soil solution increase, Considering the variation of the toxin. on both floors: the upper story is higher than the lower one and the volatility is stronger (fig 1.1).

After that, when flooded $25-30 \mathrm{~cm}$, both floors will decrease.

Another experiment: if the water was flooded regularly and maintained at a flood level of 5-7cm, during the experiment, monitoring at the $0-20 \mathrm{~cm}$ floor found that the amount of $\mathrm{Fe}^{2+}$ increased gradually and the pace of increase was like a sugar. straight for 82 days, and after that, no more.

However, the level of increase at the peak of 500ppm is not toxic to rice.

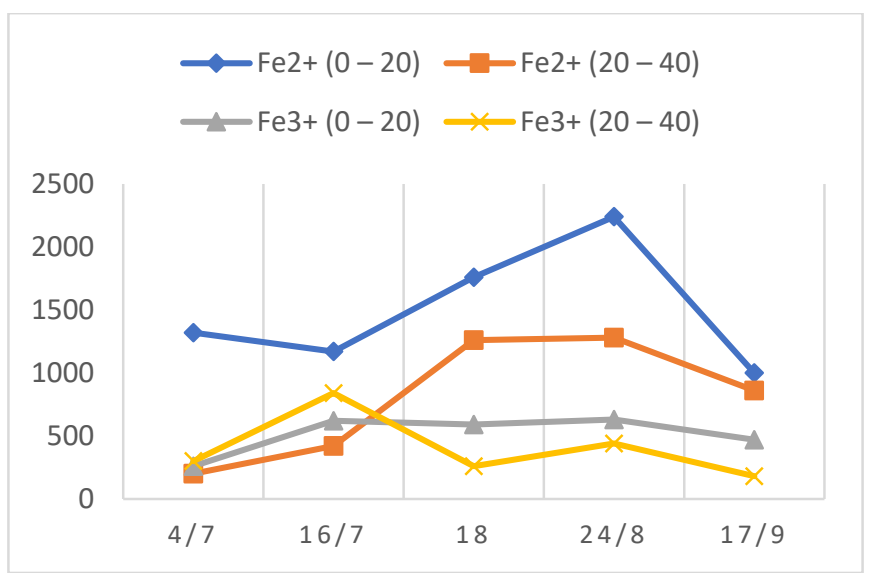

Figure 1: Graph of fluctuations of $\mathrm{Fe}^{2+}$ and $\mathrm{Fe}^{3+}$ in flooded and dry conditions

Fluctuation of $\mathrm{Fe}^{3+}$ : When submerged, it decreases and decreases rapidly in the lower layer. When dehydrated for 20 days (not completely dry), $\mathrm{Fe}^{3+}$ increases both levels. Then, if the water is flooded $15-20 \mathrm{~cm}, \mathrm{Fe}^{3+}$ will decrease rapidly (Fig 1.2 ).

Additional experiments monitoring $\mathrm{Fe}^{3+}$ in flooded conditions, after 15 days, flooding $2-3 \mathrm{~cm} \mathrm{Fe} \mathrm{Fe}^{3+}$ decreased rapidly from 319 to $62 \mathrm{ppm}$ and then decreased to $11 \mathrm{ppm}$ and then increased a little (39 ppm) at 82 days and after that, it dropped a little again at 95 days (fig 1.3). The amount of $\mathrm{Fe}^{3+}$ dissolved in little and decreased rapidly when submerged is not a concern for plants.

Thus, the increase and decrease of $\mathrm{Fe}^{2+}$ and $\mathrm{Fe}^{3+}$ are closely related to flooding and shallow. $\mathrm{Fe}^{3+}$ is not always depleted and in the interaction it is not necessary that $\mathrm{Fe}^{2+}$ increases, $\mathrm{Fe}^{3+}$ decreases.

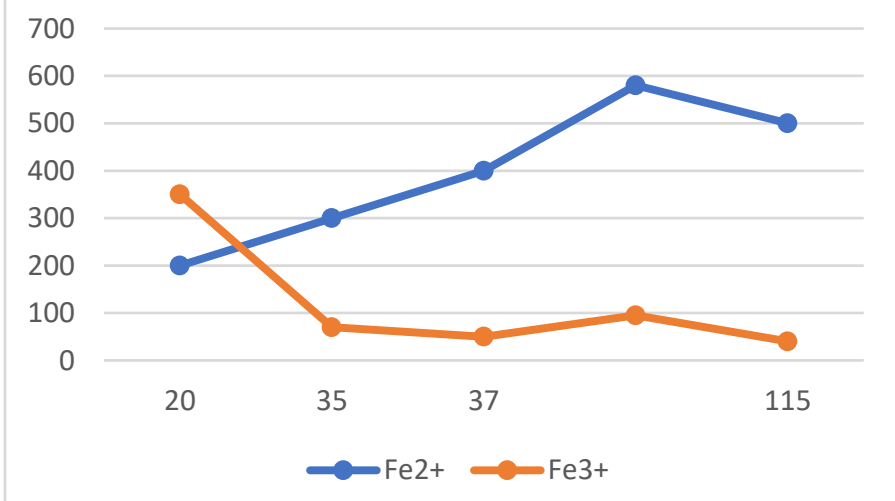

Figure 2: Graph of fluctuations of toxins $\mathrm{Fe}^{2+}, \mathrm{Fe}^{3+}$ when flooded regularly $(3-5 \mathrm{~cm})$ 
$\mathrm{Al}^{3+}$ fluctuations due to inundation and shallow water:

If left flooded $5-7 \mathrm{~cm}$, in 1 day, $\mathrm{Al}^{3+}$ in the upper floor decreased from $899 \mathrm{ppm}$ to 631ppm, the lower floor increased again (1,192ppm to 1,230ppm) To dry, the upper floor increased from 631 to 973ppm; At this level the rice plants poisoned and died. That explains the mass death of rice in "drought". But then to flood $20 \mathrm{~cm}$ for another 23 days, $\mathrm{Al}^{3+}$ on both floors will decrease and decrease rapidly (Fig 1.3).

Following the experiment in a green house pot, the amount of $\mathrm{Al}^{3+}$ on both floors showed an increase or decrease, as follows: After leaving the water (August 15) for 10 days, the upper floor increased, the lower one decreased. Thus, as in the field, in pots with a degree of drying out, but still sufficiently saturated, there was a transfer between the lower and upper layers. However, if the drying continues, both layers of the pot will increase and increase in 9/11 and 3/10 (after 26 days and 48 days) (fig 1.4).

- Experimenting on the effect of frequent flooding, we found that the fluctuation of $\mathrm{Al}^{3+}$ has the form of two peaks: - When it is just $1-2 \mathrm{~cm}$ for 15 days, the amount of $\mathrm{Al}^{3+}$ has increased a little, because in Initial low $\mathrm{pH}$ conditions $(\mathrm{pH}=3,6)$ slightly flooded water increases the amount of $\mathrm{Al}^{3+}$ released from the colloidal humus particles.

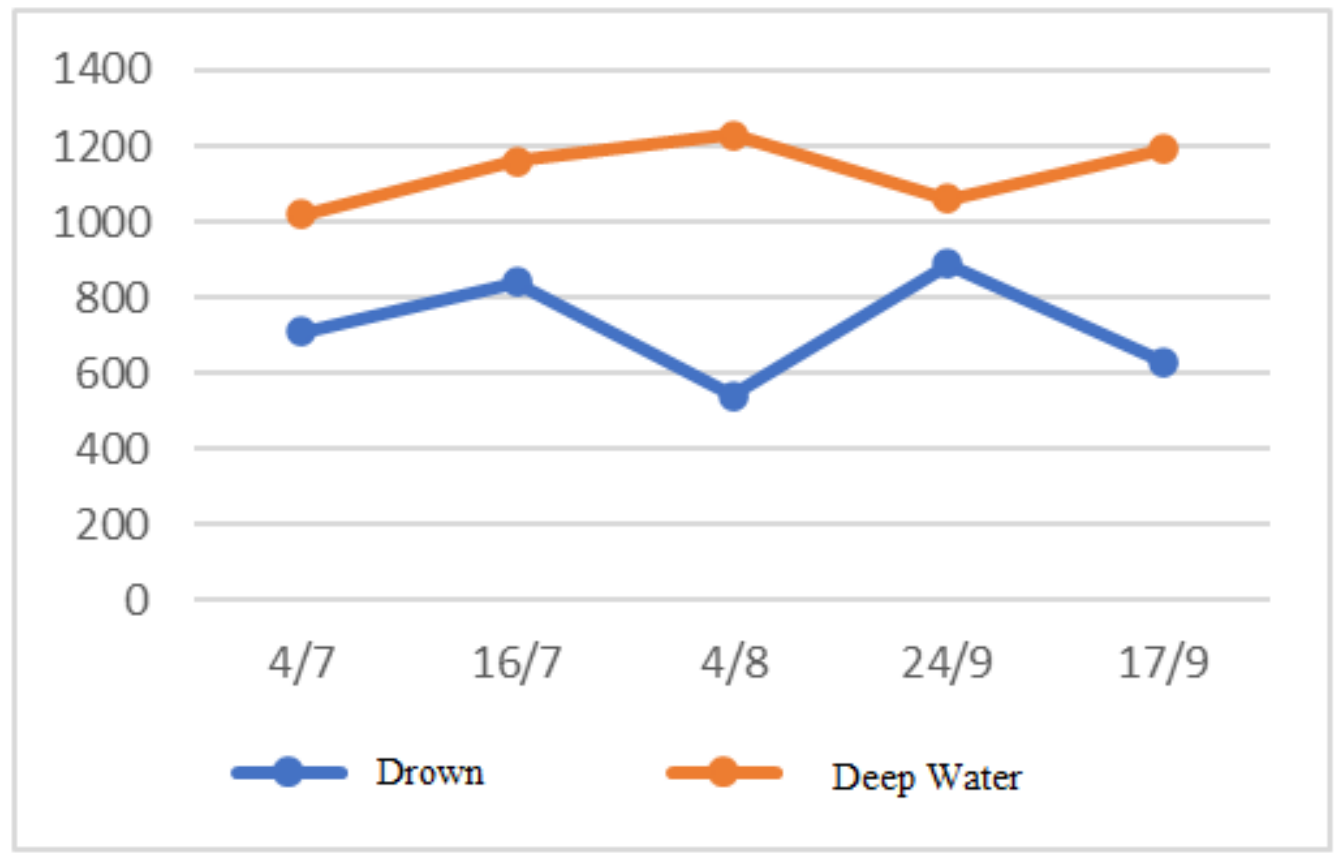

Figure 3: Graph of changes of $\mathrm{Al}^{3+}$ in field when it is dry and submerged.

- If the flooding continues for 57 more days, the amount of $\mathrm{Al}^{3+}$ will decrease to slow levels (Figure 1.5). 


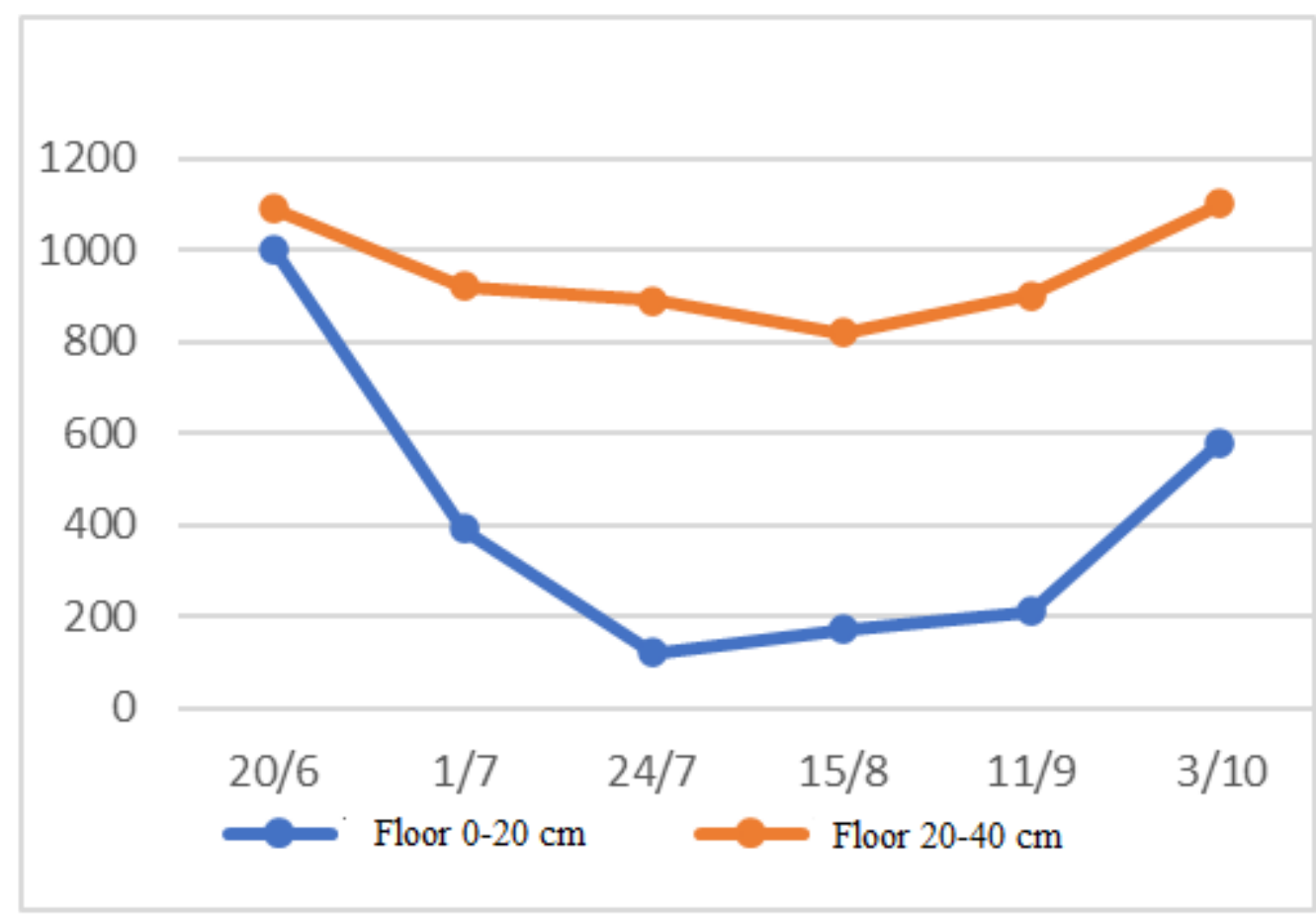

Figure.4: Diagram of $\mathrm{Al}^{3+}$ fluctuation in fields when submerged and drained (in pots)

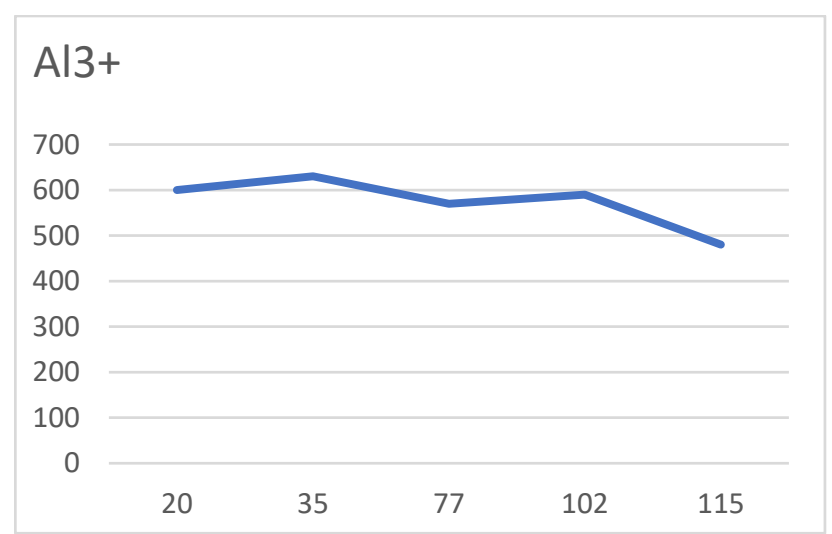

Figure 5: Graph of fluctuation of $\mathrm{Al}^{3+}$ in the field during frequent flooding

Fluctuation of toxin $\mathrm{SO}_{4}{ }^{2-}$ : When submerged 5-7 $\mathrm{cm}, \mathrm{SO}_{4}{ }^{2-}$ tends to decrease. If left to dry (drought), $\mathrm{SO}_{4}{ }^{2-}$ increased again. If the depth is $25-30 \mathrm{~cm}$ deep, the amount of $\mathrm{SO}_{4}{ }^{2-}$ decreases greatly. Thus, the amount of inundated water causes $\mathrm{SO}_{4}{ }^{2-}$, to lower the concentration ( $\mathrm{SO}_{4}{ }^{2-}$ is "lost") and the large amount of water itself also makes the concentration of $\mathrm{SO}_{4}{ }^{2-}$ in the soil solution decrease (Figure 1.6, 1.7). 


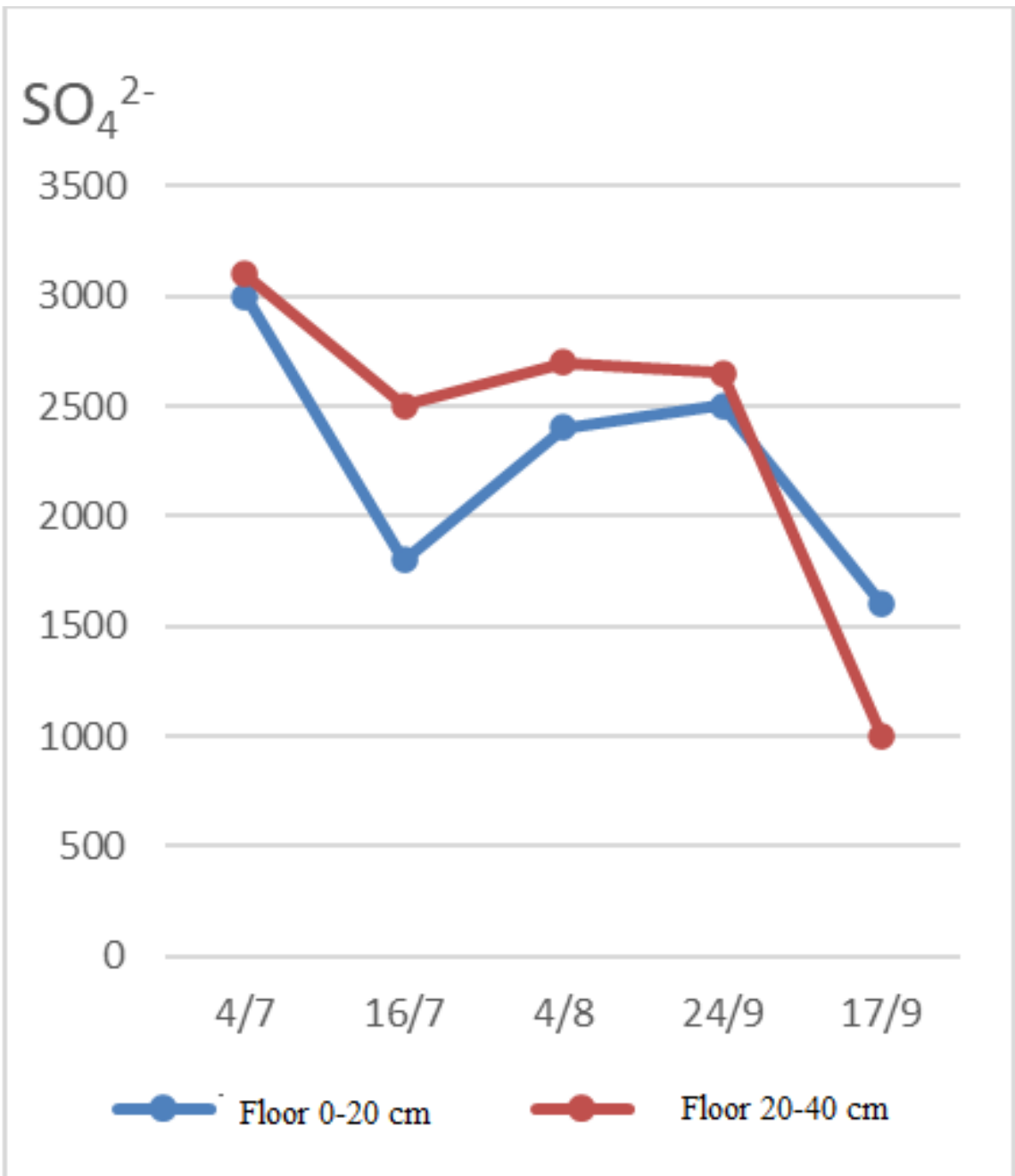

Figure 6 : Graph of changes of $\mathrm{SO}_{4}{ }^{2-}$ in acid sulphate soils due to inundation or drying out 


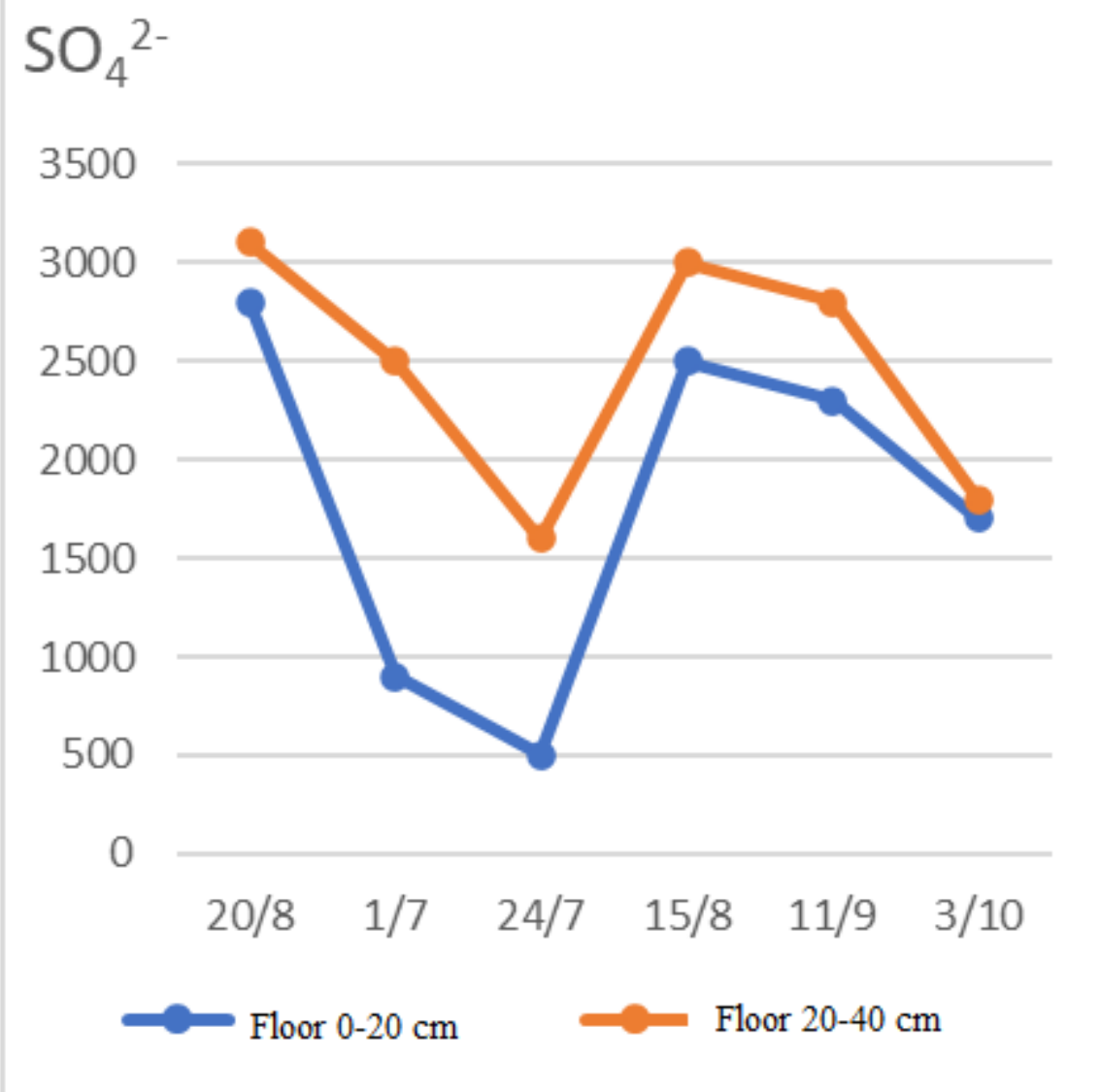

Figure 7: Graph of changes of $\mathrm{SO}_{4}{ }^{2-}$ in acid sulfate pots due to flooding or drying out

If we consider the fluctuation of ions in general, under the impact of flooding or shallow or deep inundation, we see (Figure 1.8). In both layers, the amount of $\mathrm{SO}_{4}{ }^{2-}$ fluctuated greatly, then $\mathrm{Fe}^{2+}$. Although this variation is high, the amount of $\mathrm{SO}_{4}{ }^{2-}$ is not a concern for plants. The amount of $\mathrm{Al}^{3+}$ varies slightly, but is dangerous, since it exceeds the safe limit [3] (Le Huy Ba, 1984)

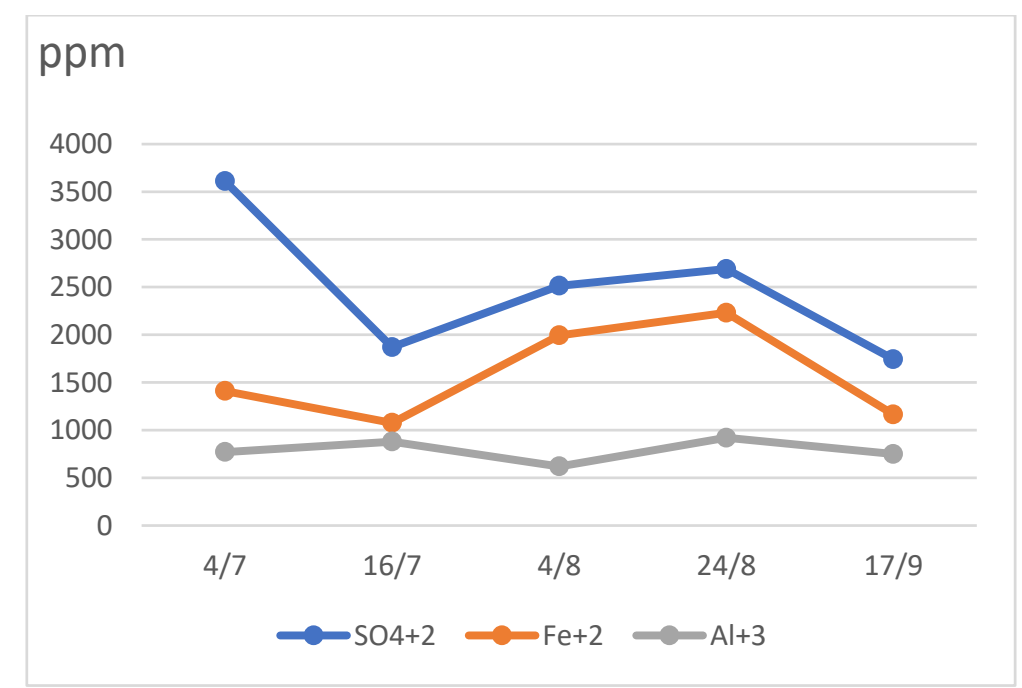

Figure 8: Deposition of changes of toxins in soil layer

+ If considering the role and impact of flooding, apply 3 tons of $\mathrm{CaCO}_{3}$ (without alum washing) because $\mathrm{Ca}^{2+}$ has released $\mathrm{Al}^{3+}$ from the soil colloid to increase the amount of toxic $\mathrm{Al}^{3+}$. The submerged children, especially over $20 \mathrm{~cm}$ deep, created a low pressure of the water to rise up along the capillaries. On the other hand, a lot of water has reduced the concentration of toxins in the soil solution. Therefore, in the present conditions, the use of rainwater and fresh water to "suppress alum" is still more economical than four people. The problem is, keeping the top layer of water in the field is necessary now and until after rice is planted. 


\section{The effect of rainfall on toxic variation}

When arranging seasons, it is necessary to base on hydro-meteorological conditions in acid sulphate soil, in addition to that factor, there is an additional factor that is: at the time of planting, whether the amount of toxins is safe or not. These two factors often come together. We have considered the effect of surface water in rice fields in acid sulfate soil. Here, we look at the rainfall factor, to the dominance of the toxin: to what extent it is safe to sow the rice seed, we have monitored the effect of rainfall on the toxin in all three layers of the Bo Bo soil. (Long An). Here, please introduce in the surface layer, the sum most related to the crop (fig ).

Consider each poison:

$+\mathrm{Al}^{3+}$ : at the beginning of the rainy season when the total rainfall Tm $<538 \mathrm{~mm}$ and the rainfall between the two sampling periods $\mathrm{tm}>193 \mathrm{~mm}, \mathrm{Al}^{3+}$ will increase when $\mathrm{Tm}$ and tm increase. This ion will reach the maximum when $\mathrm{Tm}=606 \mathrm{~mm}$ with the amount of nearly 1,000ppm (this level will cause rice death in a few days).

$+\mathrm{Fe}^{3+}$ : two-peak graph, proving that when increasing the amount of tm-sour rain exceeds $600 \mathrm{~mm}$, the increase of tm, only Fe * increases.

$+\mathrm{SO}_{4}{ }^{2-}$ when $\mathrm{Tm}>606$ can wash out and wash away quickly.

Thus, with all 3 ions, when the rainfall reaches over $606 \mathrm{~mm}$, it can wash off (this area is a typical alum area, the average alum area may have lower required rainfall).

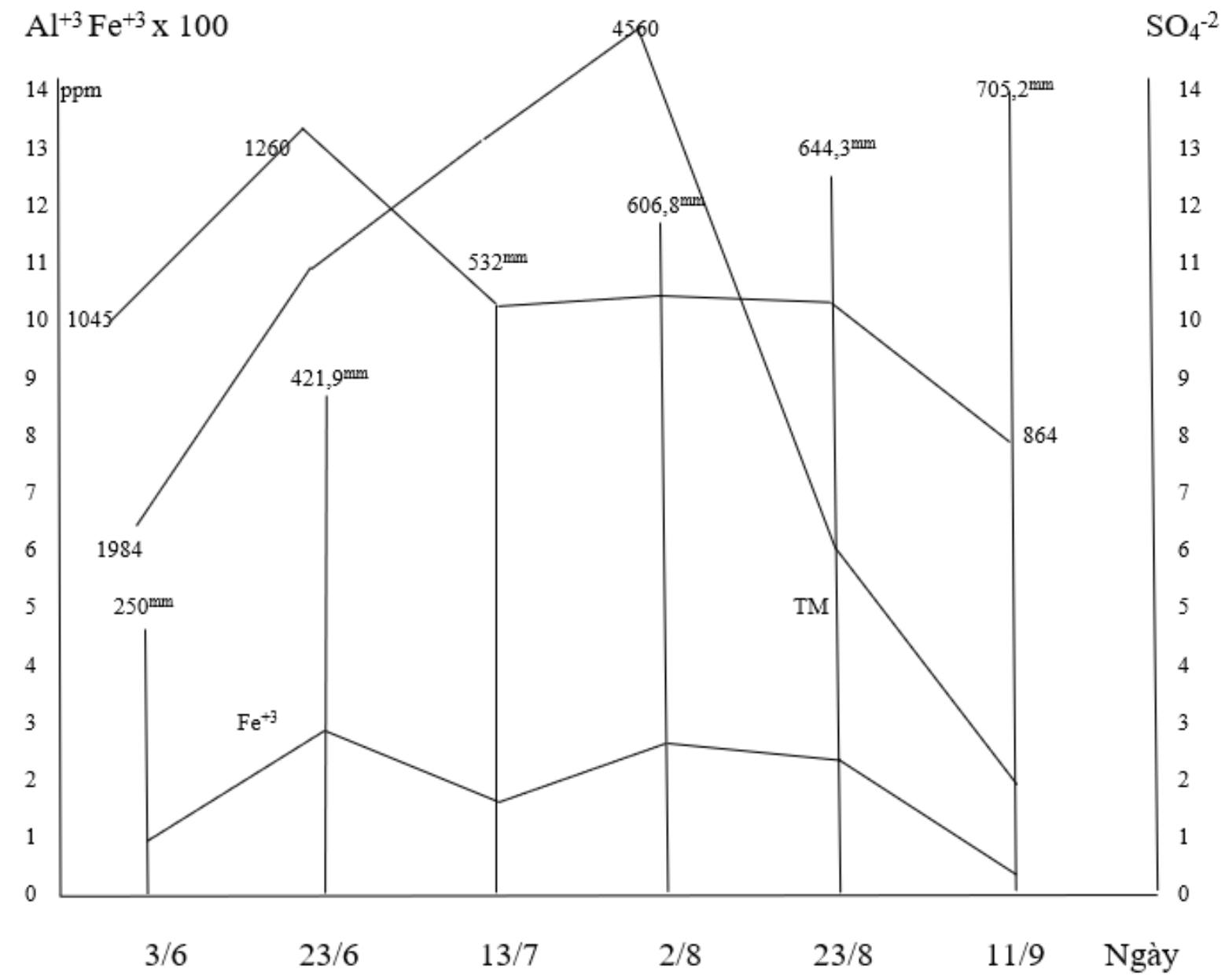

Figure 9 : Graph of the effect of rainfall in each period on toxic changes in the topsoil

Symbol Tm: total rainfall up to the monitoring time (including vertical column). tm: Rainfall between two monitoring periods (not highlighted part).

That explains why the first rains of the season are so dangerous, causing mass death of rice and other crops. Because, the amount of rain at this time is not enough to wash the alum, but only enough to dissolve the toxins, making the toxic concentration in the soil solution increase, exceeding the safety limit. Therefore, it is necessary to arrange the seasons to avoid these rains.

If the alum area has less toxic content, the crop can be arranged earlier. How can the rice plant be 2 - 3 true leaves, not having this alum absorption. 


\section{Effects of the cover plants on fluctuations of toxins}

The plants in our experiments, over four years of research, found: they have the ability to reduce toxins. Example: Growing rice crops: Comparison of paddy land with non-cultivated land and land with turf:

- $\mathrm{Al}^{3+}$ : decreases rapidly after flooding, the content is lower and more stable.

- $\mathrm{Fe}^{2+}$ : lower content, decrease faster when submerged and return to equilibrium For legumes:

Stylosanthes Gracilus, and Americana aeschinome plants not only decreased after three years of planting, but also decreased four months after planting, for example:

Table 1: Effects of stylochantes Gracilus and Aeachinome. americana with $\mathrm{Al}^{3+}(\mathrm{meq} / 100 \mathrm{~g})$

\begin{tabular}{|l|l|l|l|}
\hline Days & Control variant & $\begin{array}{l}\text { Land for planting } \\
\text { stylochanthes Gracilus }\end{array}$ & Land for planting Aechinome. americana \\
\hline $13-5$ & 4,6 & 4,6 & 4,6 \\
$10-7$ & 3,9 & 3,2 & 3,3 \\
$29-7$ & 3,4 & 3,0 & 3,2 \\
$17-8$ & 3,3 & 3,2 & 3,1 \\
$7-9$ & 3,3 & 3,0 & 2,7 \\
\hline
\end{tabular}

On the other hand, monitoring the temperature during the March days, in topsoil, where there is a carpet (at 1 pm) is the highest but still lower than where there is no secondary carpet to $6-8^{\circ} \mathrm{C}$. The temperature difference causes strong alum removal in uncovered soil.

Since then, the planting of green manure cover, or other crops with cover is very necessary (right after reclamation), otherwise it will be sulfate acidification

\section{Toxicity fluctuations when the soil is fresh and allowed to dry}

Compare the effect of soil moisture when fresh soil (45 - 50\%) compared to dry soil in the air (2 - 4\%) on the fluctuation of toxins in soil types:

- Soil is less acidition, more alum is in three layers: surface layer, jarosite layer and pyrite layer Potential acid sulfate soil (sulfaquept type) has three layers: 1-layer of brown oxidation,2 -Layer of transition and 3-layer of pyrite. - Saltification of acid sulfate soil: compare 03 layers (horizon)

Table 2: Effects of soil moisture on fluctuation $\mathrm{Al}^{3+}(\mathbf{p p m})$

\begin{tabular}{|l|l|l|l|l|l|l|l|l|l|}
\hline \multirow{2}{*}{ Soil type } & \multicolumn{2}{l}{ Floor 1 $(0-20)$} & \multicolumn{2}{l|}{ Floor 2 $(40-50 \mathrm{~cm})$} & \multicolumn{2}{l|}{ Floor 3 $(70-80 \mathrm{~cm})$} \\
\cline { 2 - 9 } & $\mathrm{T}$ & $\mathrm{K}$ & $\mathrm{T}-\mathrm{K}$ & $\mathrm{T}$ & $\mathrm{K}$ & $\mathrm{T}-\mathrm{K}$ & $\mathrm{T}$ & $\mathrm{K}$ & $\mathrm{T}-\mathrm{K}$ \\
\hline Very acid & 567 & 613,5 & $-46,8$ & 651,5 & 661,6 & $-9,9$ & 669,6 & 747,9 & $-51,3$ \\
Less acid & 22,5 & 31,5 & $-9,0$ & 93,6 & 109,4 & $-10,8$ & 69,3 & 69,3 & $-27,0$ \\
$\begin{array}{l}\text { Potential acid } \\
\text { Aluminum } \\
\text { Salty }\end{array}$ & 324 & 468,9 & -144 & 346 & 514 & -168 & 394 & 729 & -434 \\
\hline
\end{tabular}

(Note: T: wet soil; K: dry soil in the air; T - K: difference.)

- Current acid sulfate soil (in both low and more alum types) has $\mathrm{Al}^{3+}$ the difference between dry and fresh soil is small (9 - 51,3 ppm).

- Potential alkaline soil: the difference is large and the highest is in the third layer (pyrite layer): 434,8 ppm.

- Saline alum soil: 1st and 2nd floors are negligible; the third layer (containing many pyrite) has a large difference (- 348ppm).

Fluctuation of $\mathrm{SO}_{4}{ }^{2-}$ : The difference of $\mathrm{SO}_{4}{ }^{2-}$ in fresh soil compared to dry soil in the air:

- Soil is less acidic and more alum (fixed alum) has little difference (500 - 700ppm)

- There is a high difference in potential acidity soil and saline alum, especially on the 3rd floor (1,700 - 2,000ppm). 
Table 3 : Effects of soil moisture on changes in $\mathrm{SO}_{4}{ }^{2-}(\mathrm{ppm})$

\begin{tabular}{|l|l|l|l|l|l|l|l|l|l|}
\hline ground floor & \multicolumn{2}{l}{ 1 } & \multicolumn{2}{l|}{2} & \multicolumn{2}{l|}{3} \\
\hline Soil type & $\mathrm{T}$ & $\mathrm{K}$ & $\mathrm{T}-\mathrm{K}$ & $\mathrm{T}$ & $\mathrm{K}$ & $\mathrm{T}-\mathrm{K}$ & $\mathrm{T}$ & $\mathrm{K}$ & $\mathrm{T}-\mathrm{K}$ \\
\hline Alum alot & 1.800 & 2.100 & -300 & 2.100 & 2.400 & -300 & 1.300 & 1.800 & -500 \\
Less alum & 700 & 1.400 & -700 & 200 & 600 & -400 & 500 & 900 & -400 \\
Potential alum & 800 & 1.000 & -200 & 2.600 & 3.000 & -1.400 & 2.500 & 4.200 & -1.700 \\
Salty alum & 2.550 & 2.700 & -200 & 1.200 & 2.000 & -800 & 2.000 & 4.000 & -2.000 \\
\hline
\end{tabular}

Fluctuations of $\mathrm{Fe}^{2+}$ :

Table 4 : Fluctuations of $\mathrm{Fe}^{2+}$ according to soil moisture (ppm)

\begin{tabular}{|c|c|c|c|c|c|c|}
\hline \multirow{2}{*}{ Ground floor } & \multicolumn{2}{|l|}{1} & \multicolumn{2}{|l|}{2} & \multicolumn{2}{|l|}{3} \\
\hline & $\mathrm{T}$ & $\mathrm{K}$ & $\mathrm{T}$ & K & $\mathrm{T}$ & K \\
\hline Alum a lot & 76 & 26 & 20,2 & 14 & 10 & 9,5 \\
\hline Less alum & 23 & 16 & 10 & 8,2 & Vệt & Vệt \\
\hline Potential alum & 129 & 60 & 128 & 44 & 127 & 97 \\
\hline Salty alum & 185 & 35 & 58 & 40 & 54 & 20 \\
\hline
\end{tabular}

- Fresh soil $\mathrm{Fe}^{2+}$ is higher than dry soil in all 4 soil types.

- Acid sulfate soil has large potential and fluctuation of $\mathrm{Fe}^{2+}$. This fluctuation is complex, depending on microbial activity.

Table 5: Effects of soil moisture on soil pH

\begin{tabular}{|l|l|l|l|l|l|l|}
\hline \multirow{2}{*}{$\begin{array}{c}\text { Soil Horizone } \\
\text { Soil type }\end{array}$} & \multicolumn{2}{|l|}{$1(0.5-20 \mathrm{~cm})$} & \multicolumn{2}{l|}{$2(50-60 \mathrm{~cm})$} & \multicolumn{2}{l|}{$3(80-90 \mathrm{~cm})$} \\
\cline { 2 - 7 } & $\mathrm{T}$ & $\mathrm{K}$ & $\mathrm{T}$ & $\mathrm{K}$ & $\mathrm{T}$ & $\mathrm{K}$ \\
\hline Very acid & 4,3 & 4,2 & 4,6 & 4,5 & 4,3 & 4,1 \\
Less acid & 5,8 & 5,2 & 4,9 & 4,2 & 5,3 & 4,9 \\
Potential acid & 6,7 & 4,6 & 5,9 & 4,5 & 5,4 & 3,2 \\
Salty alum & 6,1 & 4,6 & 6,5 & 5,7 & 6,3 & 5,3 \\
\hline
\end{tabular}

(Note: T: fresh soil; K: dry soil)

Variation of $\mathrm{pH}$ : fresh soil has a greater $\mathrm{pH}$ than dry soil. This difference is very clear in the second and third floors of the potential acid sulfate soil (1,4 to 2,2 units). The next is the 3rd layer (pyrite) of heavy acid sulfate soil (2,1 units).

Considering the fluctuation of toxins according to moisture, we process fresh soil samples left in the air, analyzing in three periods: fresh soil (humidity $55-60 \%$ ), moist soil (15: $25 \%$ ), dry soil (2 - 4\%) with potential alum soil in Can Gio (subtype: with oxidation layer above $30 \mathrm{~cm}$, below with organic layer in the tropaquent), profile DH 147 as an example. 
Table 6: Toxic fluctuations according to moisture content in potential acid sulfate soil, DH 147 profile

\begin{tabular}{|l|l|l|l|l|l|l|l|l|l|l|l|l|}
\hline \multicolumn{1}{|c|}{ Toxic } & \multicolumn{2}{|l|}{$\mathrm{SO}_{4}^{2-}(\%)$} & \multicolumn{2}{l|}{$\mathrm{Fe}^{2+}(\mathrm{ppm})$} & \multicolumn{2}{l|}{$\mathrm{Fe}^{3+}(\mathrm{ppm})$} & \multicolumn{2}{l|}{$\mathrm{pH}$} \\
\hline Humidity (\%) & 55 & 20 & 3 & 55 & 20 & 3 & 55 & 20 & 3 & 55 & 20 & 3 \\
\hline $\begin{array}{l}\text { Horizon (layer) } \\
(\mathrm{cm})\end{array}$ & & & & & & & & & & & & \\
$0-20$ & 0,25 & 0,21 & 0,3 & 251 & 197 & 88 & 269 & 09 & 18 & 6,6 & 7,0 & 7,0 \\
$30-40$ & 0,31 & 0,3 & 0,35 & 246 & 299 & 96 & 90 & 61 & 18 & 6,2 & 6,7 & 5,4 \\
$40-50$ & 0,6 & 0,8 & 0,98 & 480 & 169 & 96 & 136 & 269 & & 6,8 & 5,2 & 4,2 \\
\hline
\end{tabular}

When the humidity is lower, in acid sulphate soil, there is potentially tropaquent:

- $\mathrm{SO}_{4}{ }^{2-}$ both tend to increase gradually.

- $\mathrm{Fe}^{2+}$ and $\mathrm{Fe}^{3+}$ decrease gradually. $\mathrm{Fe}^{2+}$ in such a fast drying process is less likely to appear as $\mathrm{Fe}^{3+}$ (dry for 7 days).

- $\mathrm{pH}$ in the surface layer increases slightly; because, in which, $\mathrm{SO}_{4}{ }^{2-}$ impact has not overwhelmed $\mathrm{Na}^{+}$(much Na: 20-22 Idl / 100) (perhaps when $\mathrm{Na}^{+}$is washed out of the upper layer, strong alum is new). As for the lower layer, although $\mathrm{Na}$ is still high, $\mathrm{SO}_{4}{ }^{2-}$ has increased by nearly $1 \%$, so the $\mathrm{pH}$ has decreased to 4,2 . Thus, the humidity makes a lot of changes to the amount of toxins.

On the other hand, moisture also indirectly affects plants through toxins.

Table 7: Soil Moisture and toxin causing permanent rice wilt

\begin{tabular}{|l|l|l|l|l|l|}
\hline Soil type & Humidity (\%) & $\mathrm{pH}$ & $\mathrm{SO}_{4}^{2-}(\%)$ & $\mathrm{Fe}^{2+}(\mathrm{ppm})$ & $\mathrm{Al}^{3+}(\mathrm{ppm})$ \\
\hline -Very acid sulfate soil: & 41,90 & 3,8 & 0,14 & 35 & 671 \\
+ IR 38(rice variety & 25,56 & 3,3 & 0,17 & 17,7 & 828 \\
+ Cà Đung (rice variety) & & & & & \\
-Grey soil: & 4,26 & 6 & Streaks & 8,13 & streaks \\
+ IR 38(rice variety) \\
+CàĐung(rice variety & 4 & 5,7 & Streaks & Streaks & Streaks \\
\hline
\end{tabular}

Experimental results The moisture of wilted plants on acid soil, with gray soil (control soil as control variant), was recorded: in gray soil, moisture was at $4.00 \%-4.26 \%$, causing wilting for both rice varieties. Because pH: $5.7-6.0$ and SO42-, Al3 + very little (streaks), in acid sulfate soil, the humidity is $25.5 \%$ for Ca Dung variety (alum resistant) and $41.9 \%$ for IR variety. 38 (less resistant to alum) caused permanent wilt for both rice varieties.

Because the poison has increased, notably $\mathrm{Al}^{3+}$. The results of experiments cultured in three solutions of conzac, knop, IRRI all showed that when $\mathrm{Al}^{3+}=100 \mathrm{ppm}$ was harmful to rice, even alum-resistant rice and when $\mathrm{Al}^{3+}=1,000.00 \mathrm{ppm}$, it caused rapid rice death. So, in acid sulfate soils, "Wilting moisture" is not only the amount of water left in the soil that is enough to cause permanent crop wilt, but also indirectly affects toxins, toxic chemicals, transforms and damages rice. when the humidity is still high (25\%).

\section{Toxicity fluctuations in redox alternating conditions}

Treat soil samples under two atmospheric oxidation conditions (symbol O) and redox alternation (let the sample dry) in a vacuum cleaner, pressure 10-2 at, 20 minutes per day - symbol OK. Each recipe repeated 3 times. Result :

Volatility of $\mathrm{Al}^{3+}$

Table 8 : Effects of oxidation conditions on $\mathrm{Al}^{3+}$ fluctuation

\begin{tabular}{|l|l|l|l|l|l|l|}
\hline Floor & \multicolumn{2}{|l|}{1} & \multicolumn{2}{l|}{2} & \multicolumn{2}{l|}{} \\
\hline Condition & O & OK & O & OK & O & OK \\
\hline Soil type & & & & & & \\
Less alum & 22,5 & 19,8 & 404,4 & 45,9 & 69,3 & 69,3 \\
Alum a lot & 567 & 517 & 651 & 628 & 696 & 556 \\
Potential alum & 324 & 414,9 & 345,0 & 356,4 & 757,2 & $1.654,2$ \\
Salty alum & 212 & 569 & 84,6 & 474,3 & 413 & 720 \\
\hline
\end{tabular}


Table shows:

- With much acidic soil, less alum: the second and third floors decrease, in contrast the first floor increases (less).

- With potential acid sulfate soils and saline alum, OK conditions are always greater than in condition 0 . Because, this transformation depends on the activity of the microbiota.

Table 9: Effects of redox conditions to fluctuations of $\mathrm{SO}_{4}{ }^{2-}$

\begin{tabular}{|l|l|l|l|l|l|l|}
\hline \multicolumn{2}{|l|}{} & \multicolumn{2}{l|}{1} & 2 & 3 & \\
Floor & O & OK & O & OK & O & OK \\
\hline Condition & & & & & & \\
\hline Soil type & 1.500 & 1.700 & 1.400 & 2.000 & 900 & 2.000 \\
Less alum & 1.600 & 2.900 & 3.300 & 4.400 & 1.300 & 3.600 \\
Plum alot & 1.000 & 1.200 & 3.000 & 3.600 & 4.200 & 6.500 \\
Salty alial alum & 2.300 & 3.300 & 2.000 & 6.500 & 4.000 & 6.500 \\
\hline
\end{tabular}

Fluctuation of $\mathrm{SO}_{4}{ }^{2-}$ : Under alternating oxidation-reduction conditions (at a pressure of 10-2 at), $\mathrm{SO}_{4}{ }^{2-}$, both increase higher under oxidation conditions, most clearly in the second and third layers of acidic soil. Potential salinity and alum (pyrite layer). In addition, we treated potential alum soil samples with $\mathrm{H}_{2} \mathrm{O}_{2}\left(25 \mathrm{ml} \mathrm{H}_{2} \mathrm{O}_{2} / 10 \mathrm{~g}\right.$ soil). The results show that the toxic change is very complicated, the main trend is to increase and the $\mathrm{pH}$ drops very quickly and greatly decreases:

Table 10: pH changes between layers when treating $\mathrm{H}_{2} \mathrm{O}_{2}$

\begin{tabular}{|l|l|l|}
\hline Horizon (layer) & $\mathrm{pH}$ before & $\mathrm{pH}$ after \\
\hline Oxidize (surface) & 5,6 & 2,1 \\
Organic & 4,2 & 1,2 \\
Pyrit & 4,1 & 1,3 \\
\hline
\end{tabular}

This proves that the oxidation capacity and potential of this soil are very high. So when growing plants, pay attention, do not let the organic layer and the pyrite layer come into contact with oxygen, otherwise the soil will become alum quickly. as in Can Gio and Dong Thap, as well as some other areas in Long An and Ca Mau that are now done.

\section{Morphological changes of the pyrite layer in the potential acid sulfate soil}

Parallel to the chemical analysis, we observed the description of alumification of the pyrite layer, when the humidity is reduced, by drying or digging the canal to dry, this can help technicians to identify each step. Alum process for acidic soils.

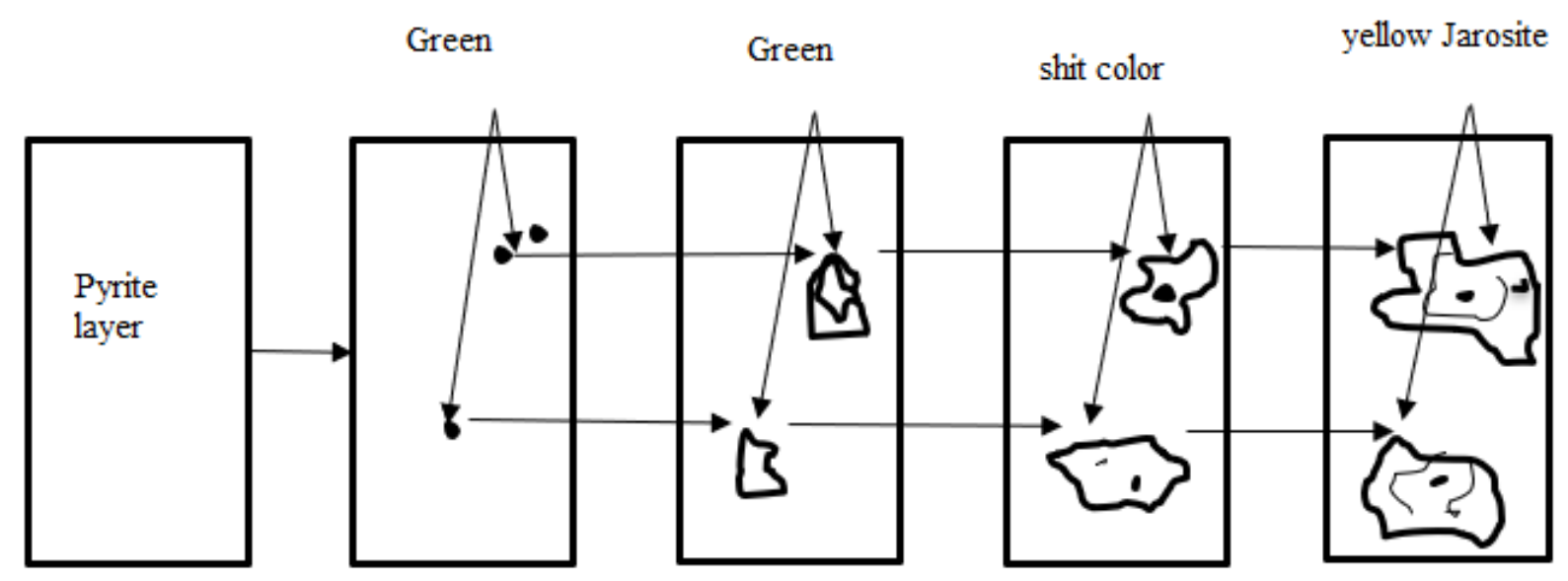

Figure 10 : Conversion diagram of alum spots in pyrite layer due to alternating oxidation

Under conditions in contact with oxygen to create alternating redox, white pyrite has converted to gray pyrite. On the gray pyrite background, small spots appear $1-2 \mathrm{~cm}$ in diameter (irregular round with light green color). The spots spread and gradually turned 
green, then gradually turned yellow "horse manure" and continued to spread, then gradually changed to $\mathrm{Fe}_{2}\left(\mathrm{SO}_{4}\right)_{3}$ "husk yellow", and of $\mathrm{K}_{3} \mathrm{Fe}\left(\mathrm{SO}_{4} 2(\mathrm{OH})_{6}\right.$; The pyrite layer has converted to jarosit: Alum has finished.

\section{Evolution of alum salts when the potential acidic soil is left dry or exposed to the organic and pyrite layers:}

Also according to the field investigation method (large sample number $n>30$ ), combined experiment arrangement, repeated three times to observe the progress of alum salts (containing many toxins). See that: in the subordinate potential alum area, when exposed or left to dry, the organic layer and the pyrite layer will have the following sequence (in sunny conditions or in the air).

Step 1: Occurrence of $\mathrm{NaCl}$ (5-10 days). On the thin, dry curled mud, or on the fleshy soil there is a layer of milky, salty, dotted, evenly spread over the ground. The higher the salinity concentration these dots are.

Step 2: Appearance of $\mathrm{FeSO}_{4}$, subtle discoloration that can only be detected through sample analysis or experience.

Step 3: Appearance of $\mathrm{Fe}_{2}\left(\mathrm{SO}_{4}\right)_{3}$ yellow straw (yellow husk) from the gaps of soil clumps and spreads until it covers the surface of the soil clump in contact with the air, forming a thick coating $0,5-1 \mathrm{~mm}$, difficult to wash off.

Step 4: Appeared $\mathrm{Al}_{2}\left(\mathrm{SO}_{4}\right)_{3}$, white than clear, consisting of small round seeds, 0,1-2 mm in diameter, or dotted with lustrous, each cluster like candy nuggets. When the air humidity is low, they are very light, brittle, and fragile. When the air is humid, they are squishy. Taste a tingling taste, numb tongue, very poisonous. This salt appears after very rapid formation processes, very easily soluble in water. After a few early rains in the season, fish and shrimp died quickly. Rice and crops are also very susceptible to poisoning and death due to the dissolution of this salt. $\mathrm{Al}_{2}\left(\mathrm{SO}_{4}\right)_{3}$ salts from the pyrite layer rose up to the ground in massively toxic clusters. In which, $\mathrm{Al}^{3+}=$ $4,26 \% ; \mathrm{SO}_{4}{ }^{2-}=38,34 \%$.

In fact, in Acid sulfate soil, there are other salts of $\mathrm{Al}, \mathrm{Fe}$, that are very complex in organic - inorganic form. Areas with dark gray or black gray layers contain high levels of this salt

\section{The formation of acid sulfate soils and its toxicity occurs}

1) in areas affected by brackish water, with tidal intrusion and with the participation of microorganisms under the following conditions and stages:

2) Next, reacts sulfuare $\mathrm{H}_{2} \mathrm{~S}$ with $\mathrm{Fe}$ in soil to form $\mathrm{FeS}_{2}$ (pyrite).

In this stage, if $\mathrm{CaCO}_{3}$ is present, alum will not be produced. But if $\mathrm{Ca}$ deficiency is present, the reaction continues at stage 3 .

3) Pyrite, if there is oxygen intrusion, will oxidize to form $\mathrm{FeSO} 4$ and $\mathrm{H} 2 \mathrm{SO} 4$ following reaction:

$2 \mathrm{FeS}_{2}+7 \mathrm{O}_{2}+2 \mathrm{H}_{2} \mathrm{O} \rightarrow 2 \mathrm{FeSO}_{4},+2 \mathrm{H}_{2} \mathrm{SO}_{4}$

4) After $\mathrm{HNO}$ acid and $\mathrm{FeSO}$ are present, under conditions of sufficient oxygen and microorganisms, free oxygen is formed:

$2 \mathrm{FeSO}_{4}+\mathrm{H}_{2} \mathrm{SO} 4+\mathrm{O} \rightarrow \mathrm{Fe}_{2}\left(\mathrm{SO}_{4}\right)_{3}+\mathrm{H}_{2} \mathrm{O}$

The dull yellow color that is formed into each seed is the yellow color of $\mathrm{Fe}_{2}(\mathrm{SO} 4)_{3}$.

According to the author here, there is also an adverse reaction:

$\mathrm{Fe}_{2}(\mathrm{SO} 4)_{3}+2 \mathrm{H}_{2} \mathrm{O} \leftrightarrows 2 \mathrm{FeSO}_{4}(\mathrm{OH})+\mathrm{H}_{2} \mathrm{SO}_{4}$

The newly formed sulfuric acid reacts vigorously with the base minerals to form aluminum sulfate and silicon hydroxyides according to the following reaction equation:

$\mathrm{Al}_{2} \mathrm{O}_{3} \mathrm{SiO}_{2}+3 \mathrm{H}_{2} \mathrm{SO}_{4} \rightarrow \mathrm{Al}_{2}(\mathrm{SO} 4)_{3}+$ Silicon hydroxyt

After that, products of $\mathrm{Na}$ and $\mathrm{K}$ will be re-created.

In fact, in acid sulfate soils, there are not only inorganic compounds but also organic alum, or organic - inorganic compounds, but the author here only talks about the reactions of inorganic compounds:

2) Next, reacts sulfuare $\mathrm{H}_{2} \mathrm{~S}$ with $\mathrm{Fe}$ in soil to form $\mathrm{FeS}_{2}$ (pyrite).

In this stage, if $\mathrm{CaCO}_{3}$ is present, alum will not be produced. But if $\mathrm{Ca}^{2+}$ deficiency is present, the reaction continues at stage 3 .

3) Pyrite, if there is oxygen intrusion, will oxidize to form $\mathrm{FeSO}_{4}$ and $\mathrm{H}_{2} \mathrm{SO}_{4}$ following reaction:

$2 \mathrm{FeS}_{2}+7 \mathrm{O}_{2}+2 \mathrm{H}_{2} \mathrm{O} \rightarrow 2 \mathrm{FeSO}_{4},+2 \mathrm{H}_{2} \mathrm{SO}_{4}$

4) After $\mathrm{HNO}$ acid and $\mathrm{FeSO}_{4}$ are present, under conditions of sufficient oxygen and microorganisms, free oxygen is formed:

$2 \mathrm{FeSO}_{4}+\mathrm{H}_{2} \mathrm{SO} 4+\mathrm{O} \rightarrow \mathrm{Fe}_{2}(\mathrm{SO} 4)_{3}+\mathrm{H}_{2} \mathrm{O}$

The dull yellow color that is formed into each seed is the yellow color of Fe2 (SO4) 3.

According to the author here, there is also an adverse reaction:

$\mathrm{Fe}_{2}(\mathrm{SO} 4)_{3}+2 \mathrm{H}_{2} \mathrm{O} \leftrightarrows 2 \mathrm{FeSO}_{4}(\mathrm{OH})+\mathrm{H}_{2} \mathrm{SO}_{4}$

The newly formed sulfuric acid reacts vigorously with the base minerals to form aluminum sulfate and silicon hydroxyides according to the following reaction equation:

$\mathrm{Al}_{2} \mathrm{O}_{3} \mathrm{SiO}_{2}+3 \mathrm{H}_{2} \mathrm{SO}_{4} \rightarrow \mathrm{Al}_{2}\left(\mathrm{SO}_{4}\right)_{3}+$ Silicon hydroxyt

After that, products of $\mathrm{Na}$ and $\mathrm{K}$ will be re-created.2) Tiếp đó, phản ứng giữa sunphuare $\mathrm{H}_{2} \mathrm{~S}$ với $\mathrm{Fe}$ có trong đất để tạo thành $\mathrm{FeS}_{2}$ (pyrite).

In this stage, if $\mathrm{CaCO}$ is present, alum will not be produced. But if $\mathrm{Ca}$ deficiency is present, the reaction continues at stage 3 .

Likewise, Van Rees (1972) states that there are three conditions for the formation of partial soil:

1) It is possible to reduce this $\mathrm{SO}_{4}{ }^{2-}$ - and it is originating from seawater and sediments, to form iron sulphides and other sulfides,

2) After that, it is necessary to have an iron sulfide oxidation medium to form $\mathrm{H}_{2} \mathrm{SO}_{4}, \mathrm{Al}_{2}(\mathrm{SO} 4)_{3}$ or $\mathrm{FeSO} 4$. The soil becomes acidic, called acid sulfate soil.

3) If $\mathrm{CaCO}_{3}$ is present in soil environent, the reaction continues in one direction: 
$2 \mathrm{CaCO}_{3}+2 \mathrm{H}_{2} \mathrm{SO}_{4} \rightarrow \mathrm{CaSO} 4.2 \mathrm{H}_{2} \mathrm{O}+2 \mathrm{CO}_{3}$

Then, $\mathrm{Na}^{+}, \mathrm{Mg}^{2+}$ which has absorbed the soil products in brackish water environment (containing more $\mathrm{Na}^{+}, \mathrm{Mg}^{2+}$ ) will be replaced by $\mathrm{Ca}^{2+}$ to make the soil better and will not become acid sulfate. But now, if there is no $\mathrm{CaCO}_{3}$, the reaction is complete in the second stage. Since then, a concept has been introduced that soil forms acid sulfate soil and its toxic when: the total number of bases is less than the total number of $\mathrm{SO}_{4}{ }^{2-}$. In other words, the $\mathrm{pH}$ of the soil depends on the $\mathrm{S} /$ base ratio. Also from that, people give an overview between $\mathrm{Ca}$ and $\mathrm{S}$ in sediments including the following four cases for the formation of acid sulfate soil:

There are four scenarios:

- Case 1: occurs when the soil is rich in $\mathrm{Ca}$ and poor in $\mathrm{S}$.

- Case 4: when it occurs in soil with little Ca but little S.

In these two cases, it is not possible to produce acid sulfate soil:

- Case 3: In low Ca soil but rich in $\mathrm{S}$, soil pellets are easy to produce alum and the alum content may be very high.

- Case 2: rich in $\mathrm{Ca}$ but also rich in $\mathrm{S}$, so the soil can produce alum locally.

The following two cases ( 2 and 3 ) occur in intertidal intertidal brackish water on old sea sediments.

The author thinks that: the presence of $\mathrm{CaCO}_{3}$ (forming $\mathrm{Ca}$ ) follows two ways: the chemical path and the biological path. In it, the chemical path prevails.

The effectiveness of $\mathrm{CaCO}_{3}$ depends on the presence of carbon dioxide $(\mathrm{CO} 2)$. Because, the more $\mathrm{CO}_{2}$ in the solution, the more $\mathrm{Ca}\left(\mathrm{HCO}_{3}\right)_{2}$ is produced in the following reaction:

Dissolved $\mathrm{CO}_{2}$ in water: $\mathrm{H}_{2} \mathrm{O}+\mathrm{CO}_{2} \rightarrow \mathrm{H}_{2} \mathrm{CO}_{3}$

$\mathrm{H}_{2} \mathrm{CO}_{3}+\mathrm{CaCO}_{3} \rightarrow \mathrm{Ca}\left(\mathrm{HCO}_{3}\right)_{2}$

Because $\mathrm{Ca}\left(\mathrm{HCO}_{3}\right)_{2}$ is easy to dissolve in water and easy to wash away for sediments, there is a lack of Ca, although there is still dissolved $\mathrm{Ca}$ in surface water. This explains the acidic soil of the Netherlands and some parts of India: although the layer below $150 \mathrm{~cm}$ contains $\mathrm{CaCO}_{3}$, the soil is still acidified because $\mathrm{CO} 2$ has lost the effects of $\mathrm{CaCO} 3$.

L.J Pons and N. Van Breeman in his article "Acid sulfate soil and rice" presented at the conference "Soil and Rice" (1977) at the Institute of IRRI gave more insight into the origin of acid soils from Moormann's point of view; to further determine the origin of the two potential alkaline soil types (potentialy acid sulphat soil) and fixed acid sulfate soil (actual acid sulfate soil).

Table 11 : Some Opstion appea and change of toxic in acid sulfate soil environment

\begin{tabular}{|l|l|l|l|l|}
\hline $\begin{array}{l}\text { Opstions } \\
\text { Materoal }\end{array}$ & 1 & 2 & 3 & 4 \\
\cline { 1 - 5 } & & & & \\
$\mathrm{Ca}$ & $\mathrm{Ca}(+)$ & $\mathrm{Ca} \mathrm{(+)}$ & $\mathrm{Ca} \mathrm{(-)}$ & $\mathrm{Ca} \mathrm{(-)}$ \\
$\mathrm{S}(-)$ & $\mathrm{S}(-)$ & $\mathrm{S}(+)$ & $\mathrm{S}(+)$ \\
\hline
\end{tabular}

(+): rich; (-): poor 


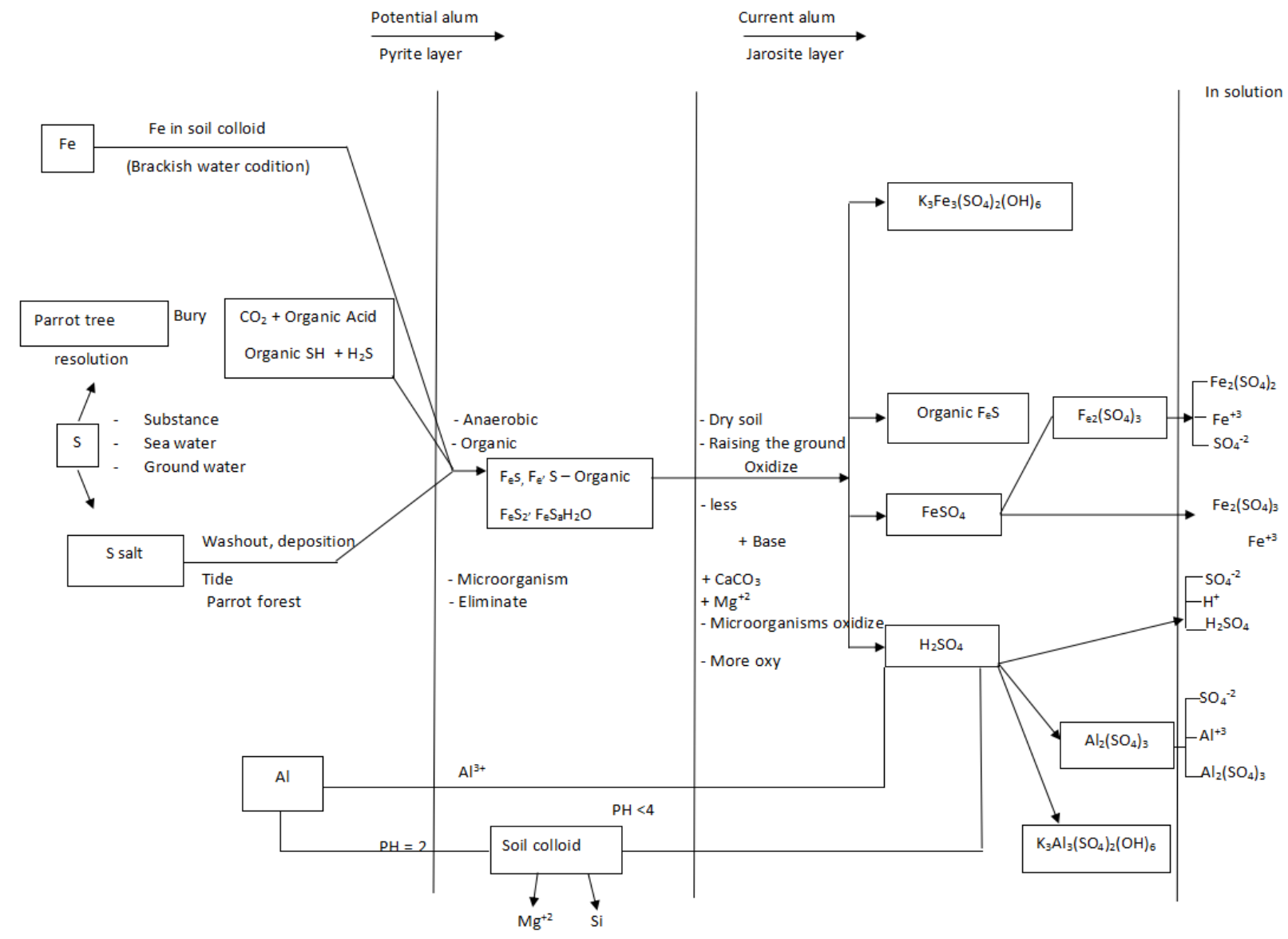

Fig 11: The formation of acid sulfate soils and its toxicity occurs

\section{Correlation between toxins in soil is much acidic}

In the above sections, we have shown that the volatility is very complex, depending on many factors. However, that volatility also has a certain rule. In order to refer to one term, we process data for most experiments and give a correlation coefficient (symbol r) in the following table:

Table12 : Correlation ( $r$ ) between toxins in acid sulfate soils in rice cultivation

\begin{tabular}{|l|l|l|l|l|l|l|}
\hline Poison pairs & $\mathrm{SO}_{4}^{2-}-\mathrm{Al}^{3+}$ & $\mathrm{Fe}^{+2}-\mathrm{SO}_{4}^{2-}$ & $\mathrm{SO}_{4}^{2-}-\mathrm{Fe}^{3+}$ & $\mathrm{Al}^{3+}-\mathrm{Fe}^{2+}$ & $\mathrm{Fe}^{2+}-\mathrm{Fe}^{3+}$ & $\mathrm{Al}^{3+}-\mathrm{Fe}^{3+}$ \\
\hline $\mathrm{R}$ & $+0,478$ & $+0,9776$ & $+0,6830$ & $+0,6018$ & $+0,7177$ & $+0,7359$ \\
\hline
\end{tabular}

(r $0.05=0.7440)$ (under no fertilization condition)

The table above shows: the toxins are usually positively correlated ( $r>0)$. In which, it is worth noting that the pairs of $\mathrm{SO}_{4}{ }^{2-}$ with $\mathrm{Fe}^{2+}$ : correlated positively and very closely; $\mathrm{Al}^{3+}$ with $\mathrm{Fe}^{2+}$ is also positively correlated. That means when $\mathrm{SO}_{4}{ }^{2-}$ increases, $\mathrm{Fe}^{2+}$ increases or vice versa. When $\mathrm{Al}^{3+}$ increases, $\mathrm{Fe}^{2+}$ increases and vice versa. From there, deducing the form of toxic ions in the soil is mainly in dissolved form $\mathrm{SO}_{4}^{2-o}$ base of $\mathrm{Fe}^{2+}$, and a little bit of $\mathrm{Al}^{3+}$.

Thus, if we have a certain effect on reducing a toxin it is possible to reduce the toxic when there is a positive correlation with it and will decrease when there is an inverse correlation between them.

\section{CONCLUTION}

Toxins in the soil environment of acid sulfate soil have very large and complex fluctuations, this fluctuation caused by natural environmental factor, depends on:

1) In case of dry out, the amount of toxins increases, which can cause rice death. To submerge the amount of toxins clearly decreased. The role is to flood rather than liming without washing alum.

2) Acid sulfate water with $\mathrm{pH}=3.8\left(\mathrm{~A}^{3+}<480 \mathrm{ppm}\right)$ can be used to irrigate rice. If it is contaminated with alum water with $\mathrm{pH}<2.9$, the soil will be acidified after only 5 to 7 days 
3) Ramping reduces toxins very quickly after a rainy season, but at the $20-40 \mathrm{~cm}$ floor, $\mathrm{SO}_{4}{ }^{2-}$ may increase but not very large.

4) When the rainfall increases $>600 \mathrm{~mm}$ (in high alum areas), there is a danger). the effect of leaching toxins (should avoid the first rains of the season for very 10 days,

5) Crops (riceplant) and green manure cover (Stylochanthes Gracilus and Aechinome, Ameriana) inhibit alum release (reduce toxicity).

6) The negative soil temperature has a great influence on the toxic fluctuation, especially for the organic layers and the pyrite layer of the soil that is highly acidic, saline and potential alum. When the humidity $=30 \%-40 \%$ makes the soil, especially acidic soils, become acidified quickly and strongly.

7) Alternate oxidation and redox conditions increase toxicity, especially in the pyrite layer and the organic layer, and metabolize very quickly.

8) Toxins in acid sulfate environment derived from sediments (only in coastal zone) contain a lot of $\mathrm{S}+\mathrm{Fe}+$ mangrove plant residue along with microbiological activity in the soil, in the condition of calcium deficiency. From there, shape the Pyrite bar, then Jarosite, followed by sulfuric Acid. In conditions of low $\mathrm{pH}$ of the environment $<2, \mathrm{Al} 3+$ will be created. The process of aid eagerly completes the production of ionic poisons: $\mathrm{Al} 3+, \mathrm{Fe} 2+, \mathrm{fe} 3+, \mathrm{SO} 42-, \mathrm{pH}<4.0$

9) The correlation of toxic ions is positive, especially $\mathrm{SO}_{4}{ }^{2-}$ and $\mathrm{Fe}^{2+}, \mathrm{Al}^{3+}$ and $\mathrm{Fe}^{2+}$. Limiting one poison can reduce other toxins,

\section{REFERENCES}

[1] Ba Le Huy (1982). The problems of acid soil in the South. General Publishing House of CM City (vietnamese )

[2] Ba Le Huy Ba (2003). Southern acid sulfate soil problems (with repair and supplement). VNU Publishing House, City CM. (Vietnamese)

[3] Ba Le Huy (1984). Evolution of Al3+, Fe2+ and SO42- ions in the country, rice in Lang Bien, Dong Thap Muoi, Mekong Delta planting rice on acid sulfate soil. Journal of Science and Technology, issue in May 1984

[4] Ba Le Huy Ba, Vo Hong Nhan, Ngo Ke Suong (1981). Fluctuations and effects of the toxin on the growth, physiological and biochemical properties of some plant varieties on Acid sulfate soil. Journal of Science and Technology University of Agriculture 4.

[5] Thuan Nguyen Duc(2001). Characteristics of some toxins in newly reclaimed heavy acid sulphate soils growing P73 in DTM area, and remedial measures. Thesis, $\mathrm{PhD}$, Agricultural Sciences, Institute of Agricultural Sciences, Vietnam

[6] Jon Pons and Van Breeman .1982. Outline of geness, characterestic,classification and improvement of acid sulphate soil (Proceeding of the International Symposium on Acid sulphate soi., Wageningen, August, 13-20, ILRI publication, 18.vol

\section{AUTHORS}

First Author - Ba Le Huy, Ho chi minh City University of Food Industry (HUFI)

Second Author - Hoan Nguyen Xuan, Ho chi minh City University of Food Industry (HUFI)

Third Author - Nam Thai Van, Ho chi minh City University of Technology (Hutech)

Fourth Author - Hiep Dang Tan, Ho chi minh City University of Food Industry (HUFI)

Fifth Author - Thanh Le Minh, Ho chi minh City University of Food Industry (HUFI)

Corresponding email: lhuyba@gmail.com 